\title{
Hardness and Stress-Strain Curves of Al-Zn-Mg-Cu Alloy Single Crystals
}

\author{
Sei Miura ${ }^{1, * 1}$, Takuro Mimaki ${ }^{2}$, Shinji Moriwaki ${ }^{2, * 2}$ and Nagato Ono ${ }^{1}$ \\ ${ }^{1}$ Department of Mechanical Engineering, Faculty of Engineering, Sojo University, Kumamoto 860-0082, Japan \\ ${ }^{2}$ Department of Mechanical and Systems Engineering, Faculty of Science and Engineering, Doshisha University, \\ Kyotanabe 610-0321, Japan
}

The present paper describes the variations of the mechanical properties of $\mathrm{Al}-\mathrm{Zn}-\mathrm{Mg}-\mathrm{Cu}$ alloy single crystals with various aging times. The cylindrical single crystals of 7475 aluminum alloys were produced at $1033 \mathrm{~K}$ by the Bridgeman method, where the composition of initial material and the shape of carbon mold were modified for the growth of quaternary crystals. The specimens proper for tensile and hardness testing were obtained from the single crystal rod homogenized at $823 \mathrm{~K}$ for $900 \mathrm{ks}$ using spark-cutting method. Subsequently, they were aged at $393 \mathrm{~K}$ for 3.6, 86.4, 900 and $2880 \mathrm{ks}$ after quenching in ice water from $773 \mathrm{~K}$. In the stress-strain curves of the alloy single crystals, the increase of yield stress and the decrease of elongation with an increase of aging time are seen together with a decrease in the rate of work hardening. Moreover, some serrations occur especially in the final plastic stage on the curves. Hardness of the alloy single crystals agrees with those of polycrystals due to the occurrence of multiple slips during loading. However, the alloy single crystals exhibit a marked decrease of yield strength in comparison with the polycrystals, which results from a single glide occurring in the single crystals. If we compare the increase of critical resolved shear stress (CRSS) derived from two kinds of theories of precipitation with the experimental value, both of them are roughly in agreement except for the specimen aged for $3.6 \mathrm{ks}$. The obtained results indicate that the maximum strength of $\mathrm{Al}-\mathrm{Zn}-\mathrm{Mg}-\mathrm{Cu}$ alloy single crystals is achieved in the transitional process between the mechanism of particle cutting and the Orowan mechanism. [doi:10.2320/matertrans.MER2008178]

(Received June 2, 2008; Accepted August 7, 2008; Published October 25, 2008)

Keywords: aluminum-zinc-magnesium-copper alloy single crystals, hardness, plastic deformation, mechanical properties, crystal plasticity, precipitation hardening mechanisms

\section{Introduction}

It is already widely recognized that the considerable improvement in strength of aluminum alloys can be achieved by precipitation hardening, as several demonstrations Osamura et al., ${ }^{1)}$ Kovács et $a l .{ }^{2)}$ and Poole et $a l .{ }^{3)}$ have shown. They investigated the relationship between the duration of the aging treatment and mechanical properties of polycrystalline 7000-type aluminum alloys. Furthermore, Chang and Huang ${ }^{4)}$ reported that the fracture in Al-Cu-Li$\mathrm{Mg}-\mathrm{Zr}$ alloys occurred along the shear bands, and thorough studies of the stress corrosion cracking were performed in Al-Li alloys ${ }^{5)}$ and Al-Zn-Mg alloys. ${ }^{6)}$

Therefore, in order to understand the mechanical behavior of $\mathrm{Al}-\mathrm{Zn}-\mathrm{Mg}-\mathrm{Cu}$ alloys which is influenced by the distribution of crystalline orientation and grain boundaries, the present authors came to the conclusion that the deformation of 7475 aluminum alloy single crystals should initially be examined. Despite the advantages that might be offered by such a study, the research has scarcely been performed so far, due to the considerable difficulties associated with the growth of quaternary alloy single crystals. The present work addresses the mechanical properties of large $\mathrm{Al}-\mathrm{Zn}-\mathrm{Mg}-\mathrm{Cu}$ alloy single crystals which were grown with the controlled composition in the mold of an improved shape. Particular attention is given to the variations of the mechanical response of the aluminum alloys prepared with different aging times.

\section{Experimental Procedure}

\subsection{Crystal growth and preparation of the specimens} Large cylindrical single crystals (size of $28 \times 100 \mathrm{~mm}$ )

\footnotetext{
${ }^{* 1}$ Professor Emeritus of Sojo University and Kyoto University

${ }^{* 2}$ Graduate Student, Doshisha University. Present address: Asahi Kasei Engineering Corp., Kurashiki 712-8054, Japan
}

were produced at the temperature of $1033 \mathrm{~K}$ by the Bridgeman method, with the growth speed of $3.6 \times$ $10^{-6} \mathrm{~ms}^{-1}$. The initial material used to prepare the single crystals was the aluminum alloy with the mass composition of Al-5.47Zn-2.18Mg-1.42Cu. That slightly differs from the content of the commercial 7475 aluminum alloys, because the grain-refining elements of chromium and titanium were eliminated. The carbon mold for the growth of single crystals was designed in such a way as to enable us to grow only a single nucleus of solidification. This was accomplished by two-stepped seed part of the mold. Furthermore, argon gas (purity of $99.999 \%$ under atmospheric pressure) was introduced into the furnace so as to avoid the dezincification.

In order to eliminate the segregation of precipitates that was observed at the interface of dendrite structure in asgrown cylindrical crystals, the homogenizing at $823 \mathrm{~K}$ was carried out for $900 \mathrm{ks}$ in the atmosphere of argon gas. Subsequently, the Al-Zn-Mg-Cu specimens were quenched in ice water after heating at $773 \mathrm{~K}$ for $3.6 \mathrm{ks}$. The aging treatment for the single crystals was performed during various intervals at the constant temperature of $393 \mathrm{~K}$. In the present work, the as-quenched sample is denoted by $\mathrm{S}_{\mathrm{q}}$, while the specimens aged for 3.6, 86.4 and $900 \mathrm{ks}$ are labeled $\mathrm{S}_{1}, \mathrm{~S}_{2}$ and $S_{3}$, respectively.

\subsection{Uniaxial tensile and hardness tests}

The Al-Zn-Mg-Cu specimens (gauge size of $1 \times 2 \times$ $8 \mathrm{~mm}$ ) proper for the tensile testing were obtained from the homogenized single crystal rod using spark-cutting method (see Fig. 1). The crystallographic orientation of the samples was analyzed by XRD Laue method, which proved that the tensile axis coincide with the [531] direction of the investigative $\mathrm{Al}-\mathrm{Zn}-\mathrm{Mg}-\mathrm{Cu}$ alloys. That orientation was determined at several locations on a cross-section of the ingot. The single sub-boundary with a misorientation of about 9 degrees was detected in the aluminum alloy. Prior to the 

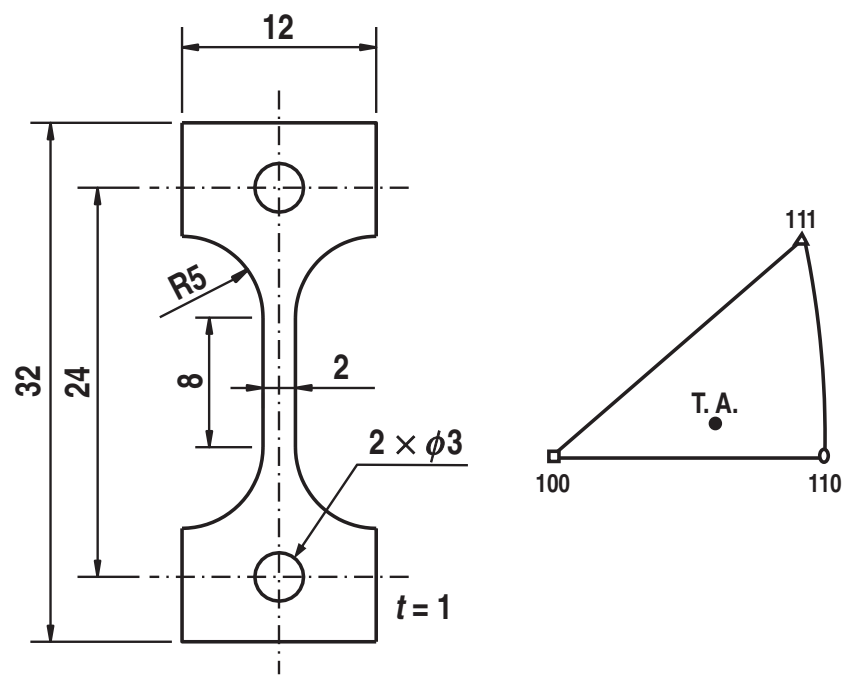

Fig. 1 The orientation of tensile axis (T.A.) and the dimensions of the specimens prepared for the tensile testing, where each unite of length is $\mathrm{mm}$.

mechanical examination, the samples were mechanically and electrolytically polished. Tensile tests at room temperature were carried out using Instron-type machine with the strain rate of $1.04 \times 10^{-4} \mathrm{~s}^{-1}$.

Hardness was measured for all samples of $S_{q}, S_{1}, S_{2}$ and $\mathrm{S}_{3}$ as well as the specimens aged at $393 \mathrm{~K}$ for $2880 \mathrm{ks}$. They were performed by means of the conventional MicroVickers hardness tester under the maximum load of $500 \mathrm{gf}$ and time equal to $30 \mathrm{~s}$. At least seven independent measurements were completed for each experimental point. In order to examine the effect of homogenization, the authors determined the distribution of hardness along the longitudinal direction in the specimen of $\mathrm{S}_{2}$ with and without homogenizing treatments.

\section{Experimental Results and Discussion}

\subsection{Tensile test}

The engineering stress-strain curves registered for the $\mathrm{Al}-\mathrm{Zn}-\mathrm{Mg}-\mathrm{Cu}$ alloy single crystals during tensile test are shown in Fig. 2. They demonstrate the increase of yield stress and the decrease of elongation with an increase of aging time, together with the change that the slope of A-B part of the curves decreases from plus to minus. The serrations observed in the as-quenched specimen of $\mathrm{S}_{\mathrm{q}}$ correspond to the usual upward type occurring due to the interaction between moving dislocations and the solute atoms under diffusion assisted by the strain-induced vacancies. In the aged $S_{1}$, the serrations with stress-drop on the stress-strain curve are intermittently observed, which is supposed to be associated with the cutting of precipitates by moving dislocations. We may notice that the obtained stress-strain curves display the serrations in their final part denoted by B and C (refer to Fig. 2), where the stress decays. Moreover, the degree of stress-drop in the serrations decreases with an increase of the aging time and disappears in the case of the specimen of $\mathrm{S}_{3}$ with the longest aging treatment. The present authors believe that the serration in question is neither related to the formation of

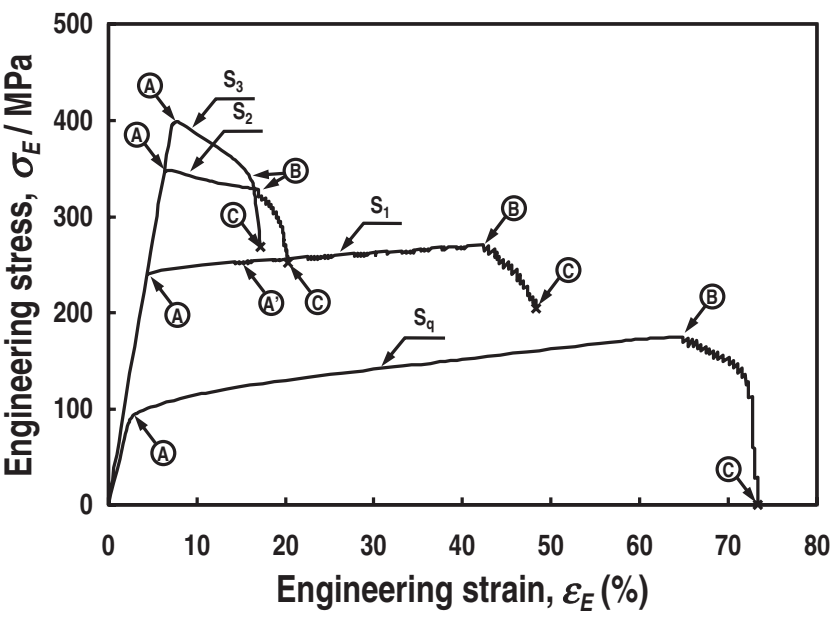

Fig. 2 Stress-strain curves registered during tensile test of $\mathrm{Al}-\mathrm{Zn}-\mathrm{Mg}-\mathrm{Cu}$ alloy single crystals. The as-quenched sample is defined by $\mathrm{S}_{\mathrm{q}}$, while the specimens aged at $393 \mathrm{~K}$ during $3.6,86.4$ and $900 \mathrm{ks}$ are denoted by $\mathrm{S}_{1}, \mathrm{~S}_{2}$ and $S_{3}$, respectively. The $A, B$ and $C$ points indicate the characteristic features in the stress-strain curves.

voids nor to their linking from precipitates, because the dimples were never observed on the fractured surface in the specimen of $\mathrm{S}_{3}$.

The deformation process of the $\mathrm{Al}-\mathrm{Zn}-\mathrm{Mg}-\mathrm{Cu}$ alloys can be shortly described in terms of the activity of slip systems. Regardless of aging time, the specimens are deformed by a primary slip system. Subsequently, the large shear bands which occur with the operation of duplex slips are formed in the central part of them, and the specimens fracture along a selected shear band. The deformation governed by a single slip corresponds to the A-B part of the stress-strain curve.

By the way, general features of the stress-strain curves of this alloy single crystal are compared to those of polycrystals previously reported by Ono et al. ${ }^{7)}$ (Fig. 1 in Ref. 7)). The results obtained for the same alloy polycrystals having the mean grain size of $83 \mu \mathrm{m}$ are shown in Fig. 3, where the as-quenched sample is defined by S-3. In addition, the aged specimens at $393 \mathrm{~K}$ during 0.6, 3.6 and $86.4 \mathrm{ks}$ are denoted by A1-3, A2-3 and A3-3, respectively. The increase of yield stress and the decrease of elongation with an increase of aging time are seen together with a decrease in the rate of work hardening. In the as-quenched S-3, the serrations of the upward type occur just after yielding and continue until the fracture. It is noteworthy that the amplitude of serrations increases with increasing the elongation. In the case of the aged A1-3, the serrations with stress-drop on the stress-strain curve are displayed after yielding. Their features could not be confirmed for the longer aged specimens of A2-3 and A3-3 (T6 aging treatment). The tendency of the disappearance of serrations with increasing the aging time is found to be the same as the results for single crystals.

\subsection{Hardness and yield stress}

Hardness of the specimens aged for 0, 3.6, 86.4, 900 and $2880 \mathrm{ks}$ is shown in Fig. 4, together with the results obtained for polycrystalline 7475 alloys by Osamura et al. ${ }^{1)}$ It is worth emphasizing that hardness of $\mathrm{Al}-\mathrm{Zn}-\mathrm{Mg}-\mathrm{Cu}$ 


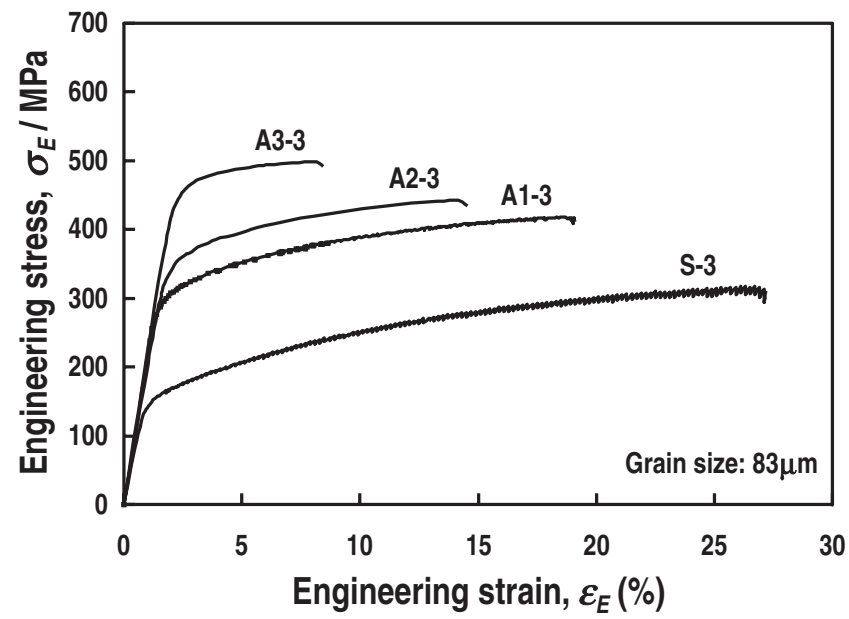

Fig. 3 Stress-strain curves of $\mathrm{Al}-\mathrm{Zn}-\mathrm{Mg}-\mathrm{Cu}$ alloy polycrystals having the mean grain size of $83 \mu \mathrm{m}$. The as-quenched sample is defined by S-3, while the specimens aged at $393 \mathrm{~K}$ during $0.6,3.6$ and $86.4 \mathrm{ks}$ are denoted by A1-3, A2-3 and A3-3, respectively (by Ono et al. ${ }^{7)}$ ).

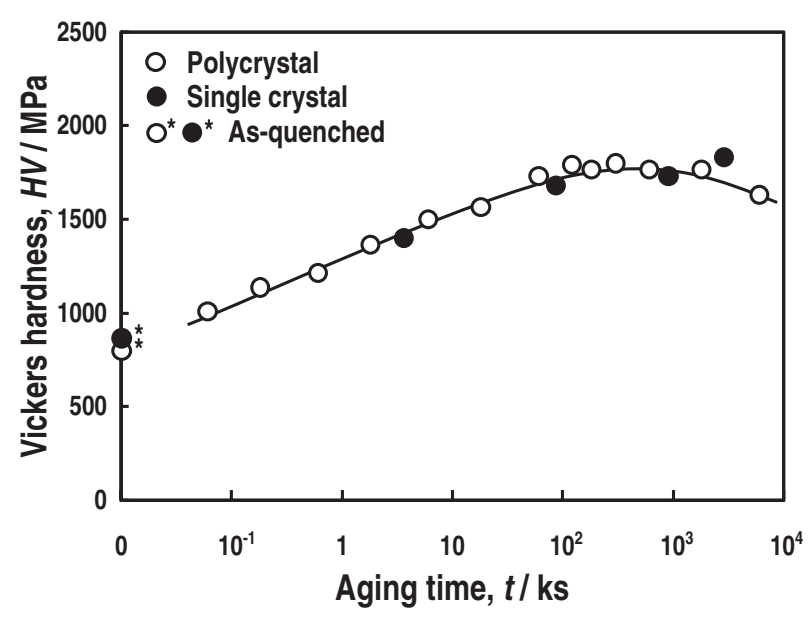

Fig. 4 Aging time dependence of Vickers hardness in Al-Zn-Mg-Cu alloy polycrystals (by Osamura et $a{ }^{1}{ }^{1}$ ) and single crystals.

alloys increases with an increase of aging time. In these alloys, it is seen that hardness and yield stress in the next discussion almost reach to the peak hardening state by aging at $393 \mathrm{~K}$ for $900 \mathrm{ks}$, and the softening of all specimens is expected by the over-aging with more long time. However, we could not confirm this fact in detail due to the shortage of the single crystals used for tensile tests, where only four specimens could be cut from the single crystal plate with the same orientation. The hardness values for the alloy single crystals are in good agreement with those recorded for polycrystalline alloys having the mean grain size of $50 \mu \mathrm{m}$ (see Fig. 4). This suggests that the grain boundaries do not affect hardness.

On the other hand, the obtained results allow us to conclude that there is a relationship between yield stress and the aging time. It was accomplished while taking the proof stresses at $0.5 \%$ strain as yield stresses for specimens of $\mathrm{S}_{\mathrm{q}}$, $S_{1}, S_{2}$ and $S_{3}$, and compared with the data for the polycrystalline alloys by Osamura et al. ${ }^{1)}$ (refer to Fig. 5). In contrast to the above hardness, the alloy single crystals

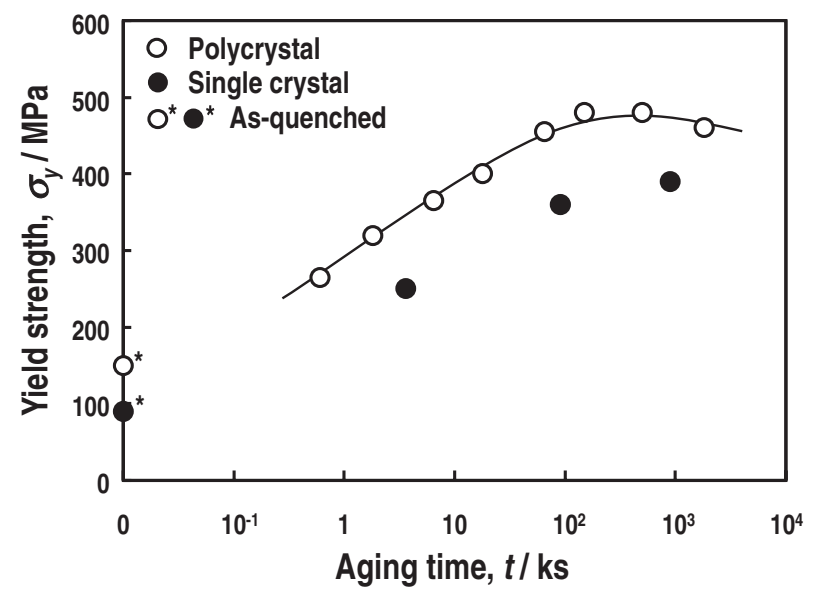

Fig. 5 Aging time dependence of yield strength in Al-Zn-Mg-Cu alloy polycrystals (by Osamura et al. ${ }^{1)}$ ) and single crystals.

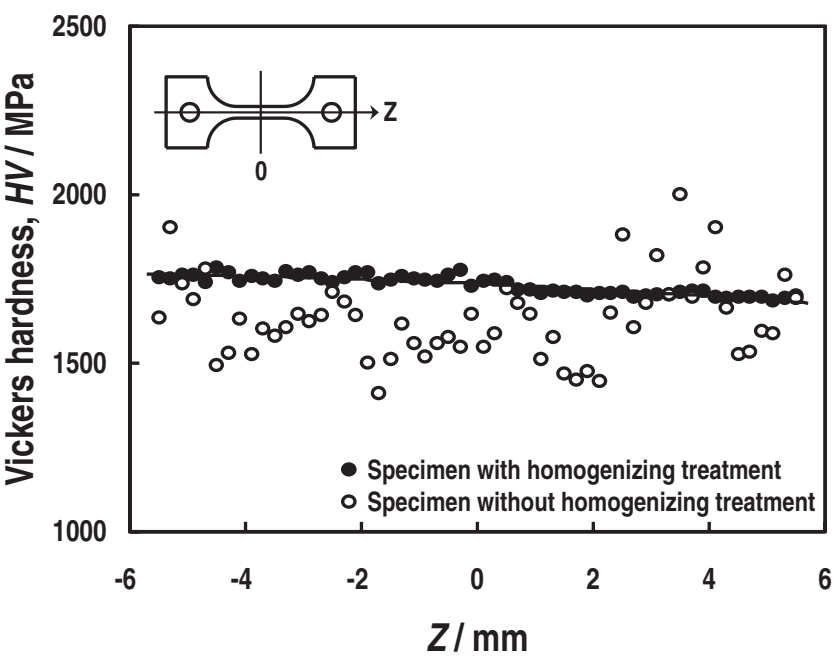

Fig. 6 The distribution of Vickers hardness along the tensile axis in the homogenized and non-homogenized specimens of $S_{2}$.

exhibit a marked decrease of yield stress, which results from a single glide with the maximum Schmid factor of 0.49 . However, the yield strength for the polycrystalline specimens is greater than that of the single crystals due to the occurrence of multiple slips in each grain. In the measurement of hardness, the strain around indentation is quite large as several percents and the multiple slips occur in the alloy single crystals during loading. Therefore, it is considered to be responsible for the fact that the difference is not almost found in hardness between polycrystals and single crystals as shown in Fig. 4.

As is mentioned in the introductory part, our specimens (Fig. 1) contained a sub-boundary which might affect the present results. However, the authors observed that the slip bands intersect the sub-grain during the tensile deformation of Al-Zn-Mg-Cu alloys. This fact implies that the effect of sub-boundary on the obtained outcome can be negligible. From the results for the measurement of hardness, it was also confirmed that the application of homogenizing did not cause dendritic segregation. Indeed, the distribution of 
hardness along the longitudinal direction in the specimen of $S_{2}$ with homogenizing treatment indicates the uniform mechanical properties as seen from Fig. 6 .

\subsection{Theory of precipitation and the present results}

Generally, it is considered that in the range of small precipitated particles before reaching the peak aged hardness, the mechanism in which dislocations cut through the particles will operate, and for large particles in the over-aging after the maximum hardness, dislocations will move by taking a path around the particles, that is the bypass mechanism of Orowan. Osamura et al. ${ }^{1)}$ analyzed both mechanisms using the theory of particle cutting by Brown and $\mathrm{Ham}^{8)}$ and the Orowan hypothesis by Hirsch and Humphreys ${ }^{9)}$ for their experimental results. It was found that the particle size in this polycrystalline alloy will be about $2 \mathrm{~nm}$ under aging at $393 \mathrm{~K}$ for $120 \mathrm{ks}$, where the largest yield stress is achieved. Since this maximum strength may be obtained in the transitional process between the above two mechanisms based on the dislocation theory, that will be roughly estimated by using the Orowan mechanism.

Hirsch and Humphreys ${ }^{9)}$ derived the theoretical formula, when Orowan mechanism is in place:

$$
\Delta \tau=\frac{0.81 G b}{2 \pi(1-\nu)} \frac{\ln \left(2 \bar{\mu} / r_{0}\right)}{\left(l_{\mathrm{p}}-2 \bar{\mu}\right)},
$$

where $G$ is the shear modulus $\left(G=26.2 \mathrm{GPa}^{10)}\right), b$ denotes the Burgers vector $\left(b=0.29 \mathrm{~nm}^{10)}\right), r_{0}$ stand for the radius of dislocation core $\left(r_{0}=4 b\right), v$ defines the Poisson's ratio $(v=1 / 3)$, and $\bar{\mu}$ is the average radius of precipitated particles. Equation (1) allows us to estimate the increase of critical resolved shear stress (CRSS) of $\Delta \tau$ due to the precipitation. Since the $\bar{\mu}$ values of $0.73,1.36$ and $1.76 \mathrm{~nm}$ were found for 7475 polycrystalline alloys by Osamura et al., ${ }^{1)}$ they were adopted for the specimens of $S_{1}, S_{2}$ and $\mathrm{S}_{3}$, respectively. Furthermore, the $l_{\mathrm{p}}$ values of the distance between particles in these specimens were similarly adjusted to equal $8.83,12.1$ and $14.2 \mathrm{~nm}$ for the polycrystals taken from the data by Osamura et al. ${ }^{1)}$ The obtained values of $\Delta \tau$ are 52, 134 and $154 \mathrm{MPa}$ for the specimens of $\mathrm{S}_{1}, \mathrm{~S}_{2}$ and $\mathrm{S}_{3}$, respectively. These values of $\Delta \tau$ are slightly overestimated because of neglecting the decrease of solution hardening during aging. However, this amount is about only $4 \%$ of the total increase with the precipitation. On the other hand, the experimental values of $\Delta \tau$ which imply the increase of CRSS can be estimated from the difference between the $0.5 \%$ proof stress for each aged specimen and that of the as-quenched $\mathrm{S}_{\mathrm{q}}$ in consideration of the Schmid factor of 0.490 . As a result, they are 75,127 and $152 \mathrm{MPa}$ for the specimens of $S_{1}, S_{2}$ and $S_{3}$, respectively. These values roughly agree with the theoretical results except for the specimen of $S_{1}$ aged for $3.6 \mathrm{ks}$.

In the case of small particles during short aging times, the increase of CRSS with the precipitation can be calculated from the following formula based on particle cutting by Brown and Ham: ${ }^{8)}$

$$
\Delta \tau=\frac{2 \sqrt{2} \Gamma^{3 / 2}}{G^{1 / 2} b^{2}} \frac{\bar{\mu}^{3 / 2}}{\left(l_{\mathrm{p}}-2 \bar{\mu}\right)},
$$

where $\Gamma$ is the energy for making the new interface per unit area due to particle cutting by dislocations. The interface energy of $\Gamma$ in eq. (2) is not known for 7475 aluminum alloys. Therefore, if we assume the $\Gamma$ value of $232 \mathrm{~mJ} \cdot \mathrm{m}^{-2}$ which was adopted in the analysis for the experimental results of this alloy polycrystals by Ono et al., ${ }^{7)} \Delta \tau$ is estimated to be 62,124 and $161 \mathrm{MPa}$ for the specimens of $S_{1}$, $\mathrm{S}_{2}$ and $\mathrm{S}_{3}$, respectively. It is noteworthy that the $\Gamma$ value of $200 \sim 230 \mathrm{~mJ} \cdot \mathrm{m}^{-2}$ was reported for the case of cobalt precipitates in $\mathrm{Cu}-\mathrm{Co}$ alloys. ${ }^{1)}$ For the specimen of $\mathrm{S}_{1}$, the obtained value of $62 \mathrm{MPa}$ is found to be close to the experimental value. It is supposed that the longest aged specimen of $S_{3}$ which indicates the maximum strength is in the transitional state between the mechanism of particle cutting and the Orowan mechanism. Although the $\Gamma$ value is uncertain, the estimated values of both mechanisms are 161 and $154 \mathrm{MPa}$, which are compared to the experimental value of $152 \mathrm{MPa}$.

\section{Conclusions}

(1) $\mathrm{Al}-\mathrm{Zn}-\mathrm{Mg}-\mathrm{Cu}$ alloy single crystals were produced at $1033 \mathrm{~K}$ by the Bridgeman method. For the growth of quaternary crystals, the composition of initial material was controlled and the shape of carbon mold was improved. The uniform mechanical properties of the specimens were achieved by homogenizing at $823 \mathrm{~K}$ for $900 \mathrm{ks}$.

(2) In the stress-strain curves of the alloy single crystals, the increase of yield stress and the decrease of elongation with an increase of aging time are seen together with a decrease in the rate of work hardening. Moreover, some serrations occur especially in the final plastic stage on the curves. Regardless of aging time, the specimens are deformed by a primary slip system. Subsequently, the large shear bands are formed with the operation of duplex slips in the central part of them, and the fracture occurs along the shear bands.

(3) Both hardness and yield strength of the specimens increase with increasing the aging time, although the hardening rate decreases. Hardness of the alloy single crystals agrees with those of polycrystals due to the occurrence of multiple slips during loading. However, the alloy single crystals exhibit a marked decrease of yield strength in comparison with the polycrystals, which results from a single glide occurring in the single crystals.

(4) By comparing the increase of critical resolved shear stress (CRSS) derived from two kinds of theories of precipitation with the experimental value, it is found that both of them are roughly in agreement except for the shortest aged specimen. This fact indicates that the maximum strength of $\mathrm{Al}-\mathrm{Zn}-\mathrm{Mg}-\mathrm{Cu}$ alloy single crystals is achieved in the transitional process between the mechanism of particle cutting and the Orowan mechanism.

\section{Acknowledgment}

The authors thank Prof. R. Nowak (Department of Physical Metallurgy and Materials Science, Helsinki University 
of Technology, Finland) for critical comments on the manuscript.

\section{REFERENCES}

1) K. Osamura, S. Ochiai and T. Uehara: J. JILM 34 (1984) 517-524.

2) I. Kovács, J. Lendvai, T. Ungár, G. Groma and J. Lakner: Acta Metall. 28 (1980) 1621-1631.

3) W. J. Poole, J. A. Sæter, S. Skjervold and G. Waterloo: Metall. Mater. Trans. 31A (2000) 2327-2338.

4) S. C. Chang and J. H. Huang: Acta Metall. 34 (1986) 1657-1662.
5) Y. L. Shen, J. J. Chan and S. C. Chang: J. Mater. Sci. Lett. 7 (1988) 787-792.

6) M. Hirano, K. Kobayashi and H. Tonda: J. Soc. Mat. Sci. Jpn. 49 (2000) 92-97.

7) N. Ono, J. Gouya and S. Miura: Trans. Jpn. Soc. Mechan. Eng. 68A (2002) 1136-1142.

8) L. M. Brown and R. K. Ham: Strengthening Methods in Crystals, ed. by A. Kelly and R. B. Nicholson, (Elsevier Book Co., 1971) pp. 9-135.

9) P. B. Hirsch and F. J. Humphreys: Physics of Strength and Plasticity, (MIT Press, 1969) pp. 189-216.

10) U. F. Kocks: Metall. Trans. 1 (1970) 1121-1143. 